American Journal of Pharmaceutical Education 2013; 77 (5) Article 91.

\title{
STATEMENTS
}

\section{Finding a Path Through Times of Change}

\author{
Katherine Knapp, $\mathrm{PhD}$, ${ }^{\mathrm{a}}$ and Jon C. Schommer, $\mathrm{PhD}^{\mathrm{b}}$ \\ ${ }^{a}$ Touro University California College of Pharmacy \\ ${ }^{\mathrm{b}}$ University of Minnesota College of Pharmacy
}

The statement, "A Looming Joblessness Crisis for New Pharmacy Graduates and Its Implications for the Academy," addresses a topic of wide discussion and increasing concern. ${ }^{1}$ Brown, who is recognized for work in this area, describes the unprecedented growth in pharmacy graduates observed since 2000 and concludes that "looming joblessness" is an inescapable outcome. ${ }^{2}$ The data, analysis, and reasoning presented are reminiscent of equally compelling data and analyses presented in 2000 that led to the conclusion that there was an acute shortage of pharmacists in the United States that would persist for 5 to 10 years. ${ }^{3}$

But things did not turn out that way. The pharmacist "shortage" slowly lessened from 2000 to 2005; and since 2006, a steady downturn in available pharmacist jobs as measured by the Aggregate Demand Index as well as many anecdotal sources, has been observed. ${ }^{4}$ A similar phenomenon was observed in nursing where the shortage of the early 2000s disappeared more or less concurrent with the Great Recession of $2008 .^{5}$ The widely accepted physician "surplus," on the other hand, gave way to a primary care physician shortage over the same period. ${ }^{6}$

From these dramatic and rather rapid workforce swings in 3 major health professions, pharmacy educators are forced to acknowledge that projections, even when based on the most solid evidence available, are not inescapable outcomes. How then should research, projections, and data trends be used? This response addresses that question and examines some of the assumptions underlying the reasoning presented in Brown's statement and offers alternative scenarios.

The authors must challenge Brown's assertion that the pharmacy academy was somehow negligent in allowing unprecedented growth to occur. The Accreditation Council for Pharmacy Education (ACPE) has been similarly targeted. This position disregards the reality that

Corresponding Author: Katherine Knapp, PhD, Professor and Dean, Touro University California College of Pharmacy, 1310 Club Drive, Mare Island, Vallejo, CA 94592. Phone: 707-638-5221. Fax: 707-638-5266. E-mail: katherine.Knapp@tu.edu. market conditions govern the educational enterprise in the United States. Attempts to block new colleges or schools or college or school expansion could be subject to restraint of trade or antitrust lawsuits based on the Sherman Anti-Trust Act of $1890 .^{7}$

While pharmacy education expansion is a key issue for the pharmacy academy, the "elephant in the room" over the last 6 to 7 years has been the weak US economy. Interpreting any phenomenon involving workforce issues requires attention to the core driver of jobs in all sectors: the economy. A 2013 study confirmed an earlier analysis showing that unemployment rates, a surrogate for the state of the economy, were the strongest driver of the unmet demand for pharmacists from 2001 to $2010 .{ }^{8}$ The study also identified graduate numbers, prescription growth rates, and Medicare Part D as less strong but significant drivers of unmet demand. While pharmacy stakeholders can anticipate that the improving economy will improve pharmacist job prospects, these other factors - including growth in the number of pharmacy graduates - may play a stronger role in the future. The authors suggest, therefore, that passively waiting for the economy to bring back a strong demand for pharmacist services is probably not the wisest course.

The federal report addressing the 2000 pharmacist shortage used the Federal Register to invite comments about the impact of the pharmacist shortage. ${ }^{3}$ It is interesting to review the broad range of respondents, which included individual pharmacists, hospitals, universities, individual pharmacies and pharmacy corporations, professional associations, the Federal Bureau of Prisons, the National Consumers League, corporations producing medications and medical supplies, and others. Faced with the overwhelming national consensus to combat the shortage, colleges and schools of pharmacy - both public and private - took action to expand class size, open new campuses, and open new colleges and schools. Thus began $10+$ years of unprecedented expansion.

As reasoned in Brown's statement, expansion per se is not harmful. Up to a certain (undefined) point, expansion can relieve the stress on previously overworked pharmacists; it serves to encourage additional training 


\section{American Journal of Pharmaceutical Education 2013; 77 (5) Article 91.}

(residencies), motivates experimentation with new roles, and provides adequate personnel to staff new services. With such compelling consensus for expansion, however, the pendulum representing the shifting balance between demand and supply likely overshot the ideal balance point.

What should be done then? As noted earlier, doing nothing is probably not the best response to the conditions outlined in Brown's statement. Rather, the pharmacy academy needs to join with other stakeholders to create the best future for graduates, practitioners, and patients in a changing healthcare system. As noted by Dr. Dennis Helling upon receiving the 2013 Remington Honor Medal, "If you don't like change, you will like irrelevance even less." "9

The pharmacy profession currently has and will continue to build capacity for contributing to the US health care system. ${ }^{10}$ However, as shifts in professional roles occur, it is important to not only monitor what might occur in the future but also to consider the rate of adoption for new innovations and new roles. The rate of adoption (including the rate of discontinuance) can help identify tipping points at which a new innovation is adopted (or discontinued) at a comparatively quick rate so that the timing of corresponding actions can be made in the health care system and in the pharmacy profession. ${ }^{11}$ Examples of past tipping points in pharmacy include counseling patients regarding the Omnibus Budget Reconciliation Act (OBRA) of 1990, drive-through service for added convenience, online adjudication of claims, pharmacistadministered immunizations, e-prescribing, and pharmacists embedded in clinics - currently, electronic health records may be reaching the tipping point. In each case, once the tipping point was reached, the majority of the profession "followed."

Once a tipping point is reached, a great deal of production capacity is required related to new service provision as well as strategic decisions regarding workforce, educational training, professional training and redeployment, updates to practice acts and regulations, new documentation and billing systems, enhanced information exchange, collaborative practice models, infrastructure, technology, policy, and new business models. Resources are scarce, so an understanding of the most appropriate timing for making such changes can lead to cost-effective use of limited resources for improving patient care. Also, by continually monitoring aspects of the diffusion of innovations in pharmacy and health care, better decisions can be made as stakeholders look to predict, shape, and experience pharmacy's future. ${ }^{12}$

The following ideas are offered for consideration as pharmacist capacity is further developed and integrated into the US healthcare system:
(1) Continual improvements to doctor of pharmacy (PharmD) training will be needed, especially the development of team-based, interprofessional training that will help health care providers learn about and experience team-based patient care. Also, expansion of pharmacy residencies (with suitable funding for such training) could help meet the advanced training requirements for pharmacists. The establishment of "industry norms" that require pharmacy residency training as a condition for certain types of pharmacist employment would help position such residencies for legitimate consideration of graduate medical education funding. Such norms also could provide assurances to other healthcare professionals regarding pharmacists' competence for providing patient care.

(2) The rate of discontinuance of some community pharmacy business models and the adoption of new business models that could help pharmacists fulfill their potential in the health care system should be monitored. Community pharmacy practice business models are still focused primarily on medication distribution. There are new models emerging in community pharmacies that use advanced logistics (eg, "centralized fill"), technology (eg, bar code scanning, e-prescribing, robotics), technicians, specialty pharmacy services, corporate (in-house) pharmacies, and new patient care service models. Where and how pharmacists might contribute to these models to ensure patient access to medications and associated services are questions that will need to be addressed. In addition, supply and demand balance or imbalance for pharmacists should be monitored as these changes to business models occur.

(3) Pharmacy practice acts and other health profession practice acts (that define scope of practice) should be updated on an ongoing basis to reflect and accommodate new roles for health professionals and for team-based care. In pharmacy, the National Association of Boards of Pharmacy (www.napb.net ) could take the lead in updating the Pharmacy Model Practice Act, which could be used by state boards of pharmacy as they develop their states' practice acts. New thinking about what embodies pharmacy practice in the health care system is continually needed. Agreement on such things as provider status and scope of practice is needed, including consensus from other health care fields and systems.

(4) Significant efforts should be made regarding the alignment of payment policies for not only supporting new pharmacist roles and services, but also to provide adequate payment for the providers of these services and evidence of cost-effectiveness for the payers of these services.

(5) The potential for flexibility in medical/health care home designs to create innovative and responsive practice structures that integrate pharmacist expertise in 


\section{American Journal of Pharmaceutical Education 2013; 77 (5) Article 91.}

medication therapy coordination and management under varying geographic regions, practice setting types, and patient population types should be explored. Balancing such flexibility with the need for standards of care is a challenge that needs to be addressed in the reforming healthcare system.

(6) Access to necessary patient health and treatment records to support and inform patient care service and decision-making functions should be secured for all members of collaborative healthcare teams, including pharmacists. Such access should include both the authority and responsibility to input information into these records to facilitate team-based collaborative care. Consensus also must be reached about what patient information is proprietary, related to business functions, and related to patient health and treatment as access to this information will have an immense impact on the ability of pharmacists to fully contribute to the developing health care system.

(7) Discussion should take place regarding bundling pharmacists' services into "episodes of care." By packaging related services together in a way that supports highquality, lower-cost care, providers, payers, and patients could begin to view episodes of care as a unified patient care experience rather than a series of disparate services. For example, products and services associated with the treatment of diabetes could be bundled in a way to influence overall pay-for-performance outcome measures. Pharmacist capacity for medication coordination throughout the whole episode of care could be valuable for improving quality and avoiding waste in medication therapy. As mentioned previously, payment redesign in addition to care redesign will need to be addressed to bring pharmacists' full capacity to fruition.

(8) Efforts should be undertaken to educate US health consumers' regarding pharmacists and the roles they play in health care so that consumers have an accurate view of phamacists' true capacity for patient care. Achieving consensus across the pharmacy profession and collaborative healthcare teams regarding processes of pharmacistprovided patient care and the language that is used to describe pharmacist-based care would have more impact on changing patients' perceptions than public service campaigns or advertising.

Responsible actions, as outlined above, will still not necessarily result in a predictable future. To this end and given the failure of past projections to predict market realities, we present 6 scenarios under which "looming joblessness" might not occur. These scenarios are presented in no particular order and more research is needed to understand the comparative impact of specific variables.

- The expansion period in pharmacy education will end. Discomfort with the continued expansion has been growing. Recent experiences with economic "bubbles" in real estate and the stock market have sensitized would-be investors (in this case, university administrators) that market directions can change rapidly and unexpectedly, leaving late entrants at great risk.

- The improving US economy will increase demand for all healthcare services, including those related to medications.

- Pharmacists will be granted provider status, enabling a broader participation in healthcare.

- The large cohort of pharmacists trained during the 1970 s, the so-called "health-provider education capitation-years" will retire in greater numbers as retirement accounts return to prerecession levels.

- The percent of pharmacists working part-time will continue to increase, requiring more pharmacists in order to keep up with demand.

- Colleges and schools of pharmacy will decrease enrollments if applicant pools drop in number and/or quality and/or jobs are not available for graduates.

Making projections and monitoring data trends are necessary but not sufficient to guarantee the best future for pharmacy graduates, practitioners, and patients in a changing healthcare system. Rather, pharmacy administrators, educators, and other stakeholders need to use the projections and data trends as tools to identify and embrace those actions that will lead the profession forward in uncertain times.

\section{REFERENCES}

1. Brown DL. A looming joblessness crisis for new pharmacy graduates: Implications for the Academy. Am J Pharm Educ. 2013; 77(5): Article 90.

2. Brown DL. From shortage to surplus: the hazards of uncontrolled academic growth. Am J Pharm Educ. 2010;74(10): Article 185.

3. Health Resources \& Services Administration. The pharmacist workforce: a study of the supply and demand for pharmacists. Rockville, MD: Health Resources \& Services Administration. December 2000.

4. Knapp KK, Shah BM, Barnett MJ. The Pharmacist Aggregate Demand Index to explain changing pharmacist demand over a ten-year period. Am J Pharm Educ. 2010;74(10): Article 189

5. Staiger DO, Auerbach DI, Buerhaus PI, Registered nurse labor supply and the Recession-Are we in a bubble? N Engl J Med. 2012;16:1463-1465.

6. Jolly P, Erikson C, Garrison G. U.S. Graduate Medical Education and Physician Specialty Choice. Acad Med. 2013: Feb 19. [Epub ahead of print].

7. Act of July 2, 1890(Sherman Anti-Trust Act), July 2, 1890; Enrolled Acts and Resolutions of Congress, 1789-1992; General 


\section{American Journal of Pharmaceutical Education 2013; 77 (5) Article 91.}

Records of the United States Government; Record Group 11; National Archives.

8. Taylor TN, Knapp KK, Shah BM, Barnett MJ, Miller L. Unemployment, pharmacy graduates, prescription growth rates and Medicare Part D affect the unmet demand for pharmacists: A statelevel analysis using Aggregate Demand Index data. J Am Pharm Assoc. In press.

9. Helling DR. 2013 Remington Honor Medal Address. http://www. pharmacist.com/dennis-k-helling-receives-remington-honor-medalhighest-honor-pharmacy. Accessed April 82013.
10. Schommer JC, Planas LG, Johnson KA, Doucette WR, Gaither CA, Kreling DH, Mott DA. Pharmacist capacity for contributions to the reforming US healthcare system. Innov Pharmacy. 2010; 1(1): Article 7.

11. Rogers EM. Diffusion of Innovations. $5^{\text {th }}$ ed. New York, NY: Free Press; 2003.

12. Schommer JC, Clince RR, Uden DL, Larson TA, Hadsall RS, and Schondelmeyer SW. Pharmacy looks to the future. In: Smith MI. Fincham, JE, Wertheimer A, eds. Pharmacy and the U.S. Health Care System. 3rd ed; 2005:417-443. 